\title{
Digital Trainer for the Development of the Fine Motor Ability in Children with Cerebral Palsy
}

\author{
Jonnathan Berrezueta-Guzmán, Luis Serpa-Andrade, Vladimir Robles-Bykbaev and Eduardo Pinos-Velez
}

GIIATa, Universidad Politécnica Salesiana, Calle Vieja 12-30 y Elia Liut, Cuenca, Ecuador

\begin{abstract}
The leading cause of disability in Ecuadorian children is cerebral palsy, this disorder in most cases produces a deficiency of the ability to move fingers, hands and wrists at various levels, this happens too with the intellect of the patient. Many of the treatments and therapies are seeking that the patient can develop all of your motor ability and intellectual skills, using activities that involve the part Intellectual and practicality of their extremities. Today technology gives us the opportunity to manage devices of aid and assistance that not only complement the daily activities that are performed during the therapies in the help centers, they need to give results that show leaps and bounds in the progress that you want to get. The purpose of this project is to make a device that helps a patient to develop their fine motor ability to the patient can use their hands, fingers and wrists movements in various ways in coordination with their vision in conjunction with occipital lobe causing that brain activity in the patient, present alterations of amplitude in the beta waves in the hemispheres of the brain that allow move muscles, with only maneuver a fully digital device and low cost. These brain and muscles signals will be analyzed in this project, to test the efficiency of this project.
\end{abstract}

\section{Introduction}

These days, the cerebral palsy is associated as synonym for the spastic diplegia, in the past this disability was known as "Little disease" in honor to the doctor Wiiliam Little who wrote in 1844 about the influence of the abnormal childbirth in a clinical picture. It is so spoken of cerebral palsy from the years 1889 and has detailed as the result of encephalitis due to congenital factors and prenatal complications. [1].

INEC (Ecuadorian Institute of statistics and censuses) in the publication of the final results of the censuses of population and housing in 2010, shows that in Ecuador the $2.77 \%$ of the population has some kind of disability (in numbers means 401.538 people), this value is observed in Figure 1, 48\% (in numbers means value of 191.384 people) has some sort of physical or motor disability and $22 \%$ (90.259 people) disability intellectual, these percentages it is estimated that one-third is associated with people who suffer from cerebral palsy and that his medical chart shows these disabilities are most present in children, so has come to regard the cerebral palsy as the main cause of physic and intellectual disability in children in Ecuador, data are worrisome concerned to the population of an underdeveloped country, since in many cases there is not possible to establish what was the real cause of cerebral palsy in a child. [2]

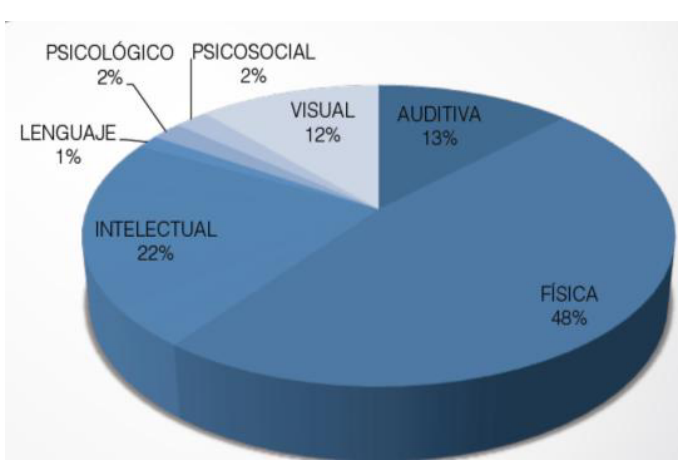

Figure 1. Statistics of classification of disabilities in Ecuador. Data obtained from 2010 in a population census and this data is thinks that is increasing with the population increasing and underinvestment in special medical care, compared to other countries [3].

The Institute of Cerebral Palsy (IPCA), is located in the province of Azuay, this is an institution non-profit which is home to almost a hundred of people with cerebral palsy like children and adults from different social classes. Here each patient presents a different medical chart, each child or teen is a one world seeing from a medical point, and these patients have from a low to a high level of disability.

The implemented project, aims to cover treatment for the improvement of the fine-visual moving ability, giving the patient a physical interaction with the device through hand, fingers and wrists movements doing nervous 
stimuli in the hemispheres of the brain with the occipital lobe to work in conjunction with the muscular forearms (flexor and extensor) to stimulate to the patient to resolve the problems raised by the device.

\section{Demonstration and impairment of fine motor action in patients with $\mathrm{CP}$}

Cerebral palsy is manifested in different ways, whether it is affecting the physical part as the intellectual part of the patient, or both simultaneously, depending on the features of disabilities, to cerebral palsy can classify it from different points of view, in various bibliographic materials are classifications that include topography, degree, tone and even dysfunctions associated with cerebral palsy, but the most general is the classification according to the type; of this classification exists:

- Spastic type, is which interfere with the realization of voluntary movements due to muscle spasms that the patient presents at the time of performing some action. [4] - Type athetosis, which has involuntary movements in the extremities that generate the bad ability to maneuver with their hands, fingers and wrist. [5]

- Type ataxia which is characterized by the lack of coordination in the March and the motor ability both fine as thick, due to alterations in posture of the body. [6]

- Finally a patient may show a picture that presents the combination of these three types, which is called mixed type by this combination. [7]

As denoted in the classification, motor action is the most involved, this is due to damage in the afferent and efferent pathways of the cortex, where the first receive sensory information and the latter make the motor activity, within these lines stands a pyramid system and an extrapyramidal and is the first of these which is in charge of voluntary fine movements, then here the communication of the cortex of the brain with the marrow is affected since the Synapse between the medullary and cortical neuron only performs all the way and there is a dysfunction in the efferent pathways the pyramidal system that collapses, and does not perform the communication necessary to transmit stimulation action members who make up the fine motor skills as well as postural balance mechanisms creating even abnormal reflexes. [8]

\section{Pedagogical approach to the treatment of the CP}

The physiotherapy field considers the educational part as a key pillar in the rehabilitation medical, guiding their treatments to passive and active muscles stimulating because that has been shown in previous studies that the various applications that are carried out in the physical therapy schools encourage the development of motor and intellectual part of the patient. However although not always the therapists work with multidisciplinary psychopedagogical insight that develops a necessary educational technology, then these are not applied and therefore is not always fulfilled the objectives mentioned above. [9]
Develops a process in which is set a note of voluntary movements not reflexes, this serves to be able to estimate the capacity of development of motor coordination with the intellect and thus establish what the activity neurodevelopmental of the child to be a success this observation technique of motor behaviors with the intellectual dexterity Unable to provide any technical and technological aid that each case requires. $[10,11]$

\section{The proposed system}

User machine is an embedded system that resembles a digital whiteboard, which offers the user a very attractive and eye-catching interface for interaction, controls are friendly so that the therapist can provide first configurations so that the patient can use. Hardware is resistant and comes recorded instructions, so it can be used properly.

The purpose of this device is to improve fine motor ability of the patient with cerebral palsy, promoting exercise and coordination of the fingers of the hands, but above all the rotation of the wrists doing that the muscles of the anterior compartment (flexor) and the muscles of the posterior compartment (extensor) of the forearm work of more intensely in coordination with vision.

The trainer is a combination of an Android device with a driver that allows the user to contact indirect with the Tablet so that controls programmed in the PIC may serve as machine user interface to enable the patient to perform the activities planned in the application.

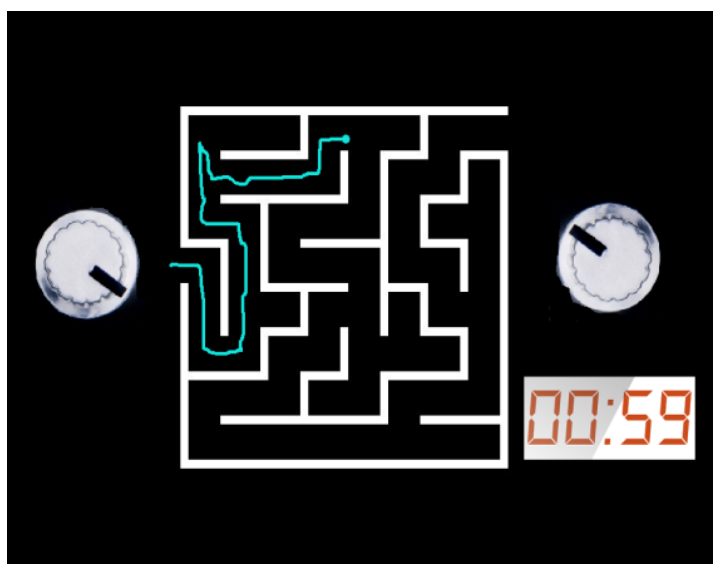

Figure 2. Screenshot of the device interface in configuration mode use of knobs, where tells you the movement to be carried out and realize the exercise and the time spent in this.

The device has knobs, sliders and led's buttons that act depending on settings preprogrammed by the therapist, each control has a purpose in specific, either be required fill a picture with colors or solve a maze, and these controls are intended to put to the test the movements of fingers, hands and wrists in coordination with the vision.

The device is intended to train the patient, so that her fine motor ability see developed, every case is a different section but is observed that in the majority of cases these children with the disabilities present a pattern, is a signal that although distorted (as usually the brain signals) has a repeating pattern can be identified, this tells us the lack of 
stimulation in brain activity then this repeating pattern must be broken, and to know if it is fulfilling this goal, is analyzed brain signals issued by the child when is using the device, this happens same with the muscles signals in fingers, hands and wrists.

\section{Preliminary results}

The device was tested in the Cerebral Palsy Institute of Azuay (IPCA), a Center non-profit whose primary function is to provide specialized care to people who have this disability, tests were considered successful since it obtained an excellent acceptance of the patients, in addition with the encephalographic analysis was seen that it breaks completely preliminary settings of brain activity obtained prior to the use of the device as shown in Figure 3. Same it happens in the muscle analysis as shown in Figure 4.

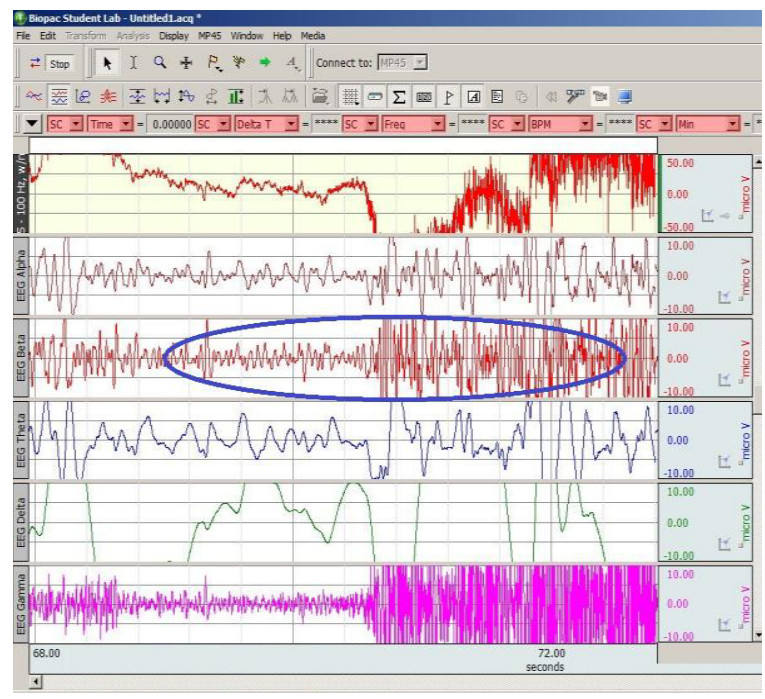

Figure 3. Results of the cerebral signal in beta waves that is obtained by the device "Student Lab MP45 BIPAC"; is observed that the amplitude and frequency changes drastically pattern that was established, when it starts to solve a problem in the trainer device.

Beta waves was seen be altered in its amplitude and frequency, which indicates that the patient concentrates her brain activity in solving the programmed problem in the device and tries to coordinate their hands, fingers and wrists for the resolution of what he sees.

The most appreciated in visual form results, we can corroborate that the patient shows a promising picture on their fine motor mobility at the moment which is using device, so it is said that the device is very effective making that patient can be greater activity in their left and right hemispheres so they coordinate their right hand and left respectively as well as the back of the brain at the time of visually guided in the development of games of speed and visual coordinating.

If we go to spectral analysis of muscle activity that runs on the hands and wrists when using the device fingers shows that the myoelectric signals received respond with a significant excitement about when these limbs are at rest, so muscle activity with brain activity represent a continuous improvement to the fine motor skills of the child.

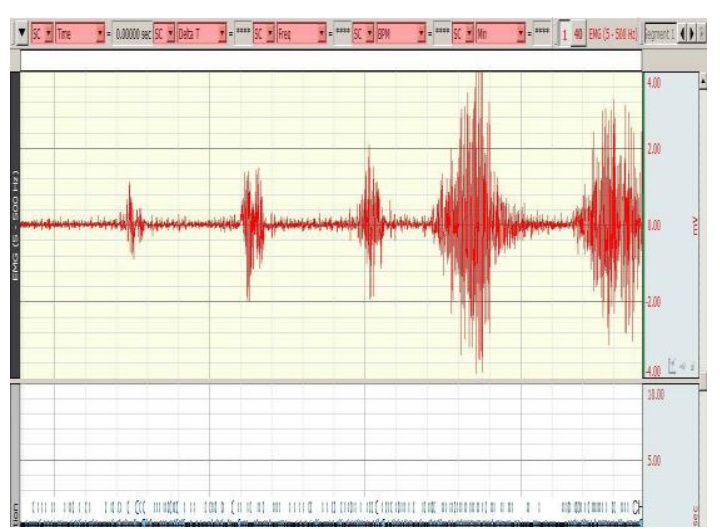

Figure 4. The electrical activity in the muscles that are running movements of the fingers, hands and wrists are affected very significantly as the device operation progresses, this electrical signal is coordinated with the brain signal.

After some weeks of tests, we set a track record that shows patients who used the device and the results obtained in all of them. Table 1 shows how many and ages of the children who were to implement the corresponding tests with the device.

Table 1. Ages and number of children with CP that participated on the experiment with authorization of the institute and their parents respectively.

\begin{tabular}{|c|c|c|}
\hline Age (years) & Boys & Girls \\
\hline $\mathbf{4 - 6}$ & 9 & 6 \\
\hline $\mathbf{7 - 9}$ & 18 & 18 \\
\hline $\mathbf{1 0 - 1 2}$ & 14 & 9 \\
\hline
\end{tabular}

Figure 5 shows the results of feasibility and acceptance of the device, this graphic is very promising and expected results the device had a $92 \%$ acceptance in boys and girls of the Institute, also in this sample was obtained $100 \%$ of alteration in brain waves that breaks repetitive parameters of these signals and amplifies the signals Beta (signals issued by the brain when it is in a moment of concentration or solving a problem) as shown in Figure 2, the same happens to the electrical impulses emitted by muscle activity, these signals are coordinated with the cerebral activity, such as shown in Figure 4.

\section{Results feasibility device}

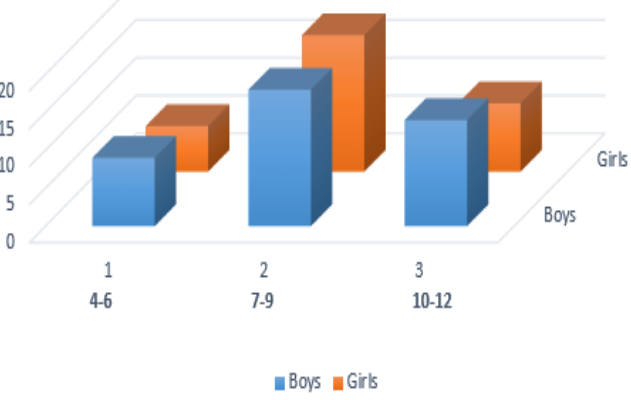

Figure 5. Preliminary results of the pilot experiment (in acceptance terms and good results). 


\section{Conclusions}

This paper shows how we designed a device that combines a Smart technology with a control system that helps a patient with cerebral palsy improve their fine motor skill in coordination with visual activity, it also checks that intellectual activity also is affected, run different exercises established problems.

The benefits that shows the device is showing greater effectiveness the rest of the toys and teaching material that was used so far, however this device no longer only a support to the therapies carried out the teacher or therapist from the Center, but is a joint work with excellent results.

The results of the analysis of brain activity and muscle shows the coordination were expected from the use of this device, testing continues and results are increasingly promising, the therapist and the patient can see the changes that are generated gradually in their ability to move fingers, hands and wrists in a coordinated manner, not only by using this device but also to perform other coordination activities like holding objects and move them.

Cerebral palsy is a field of study that gives us many issues, but the engineer can respond with different ways of development of elements and equipment for remedy, therefore, for a disease that has no cure, the only thing we look for is help for improve the quality of life of these patients (mostly children) putting into practice our knowledge.

\section{Acknowledgements}

We would like to thank Dr. Hernán Tenorio and all the collaborating people from Instituto de Parálisis Cerebral del Azuay (IPCA).

\section{References}

1. Cruickshank, W. M., Hallahan, D. y Bice, H. V. Personality and Behavioral Characteristics. En W.M. Cruickshank (ed.): Cerebral Pal.vy. A developmental disabiliry. New Yark: Syracuse University Press, (1976)
2. INSTITUTO NACIONAL DE ESTADÍSTICA Y CENSOS. Boletas Censales período 1950-2010. Quito,<http://www.ecuadorencifras.gob.ec/document os/webinec/Publicaciones/Evolucion_variables_1950 2010_24_04_2014.pdf>

3. CONSEJO NACIONAL DE IGUALDAD DE DISCAPACIDADES, Ecuador sacado de: < http://www.consejodiscapacidades.gob.ec/wpcontent /uploads/downloads/2015/09/estadistica_conadis.pdf $>$

4. Illescas Vásquez, Margarita Raquel, Desarrollo de un software educativo para el Instituto Fiscal Especial "Stephen Hawking" en el área de Lenguaje y Comunicación para niños con parálisis cerebral nivel 1; directora Paola Cristina Ingavélez Guerra. Cuenca [Ecuador], (2010)

5. Gesell, A. y Amatruda, C. S. Developmental diagnosis: Normal and abnormal child development. Hagerstown, Md: Harper and Row (trad. cast.: Diagnóstico del Desarrollo Nomnl y Anormal del nifio. 1979. Buenos Aires: Paidós.), (1941)

6. Crickmay, M. (1966). Speech Theropy and the Bobaih Apprmch ro Ci;ebral Pnlsy. Springíield. Illinois: Thomas (trad. cast.: Logopedia y enfoque Bobath en Parálisis Cerebral. Buenos Aires: Panamericana), (1974)

7. Bobath, K. y Kong, E. Zerebrale Bewqungsst8rungen Beim Kind. Müchen: S. Karger-Basel (trad. cast.: Transtornos Cerebromotores en el niiio. 1986. Buenos Aires: Panamericana), (1976)

8. Hernández Gómez, R. DejFciencias Cerebrales Infantiles. Madrid: Pablo del Rio, (1977)

9. Delmas, A. Vias y Centros Ndrviosos. Barcelona: Toray-Massoy, (1973)

10. Phelps, W. M. The role of physical therapy in cerebral plasy and bracing in the cerebral palsied. En orrhopaedie appliances Arlas, 1, 251-522 1952

11. Milani-Comparatti, A. y Gidoni, E. Pattern analysis of motor development and its disorders. Developmenral Medicine and Child Neurology, 9, 625-630 (1967) 